\title{
ANÁLISE MULTITEMPORAL DO USO E OCUPAÇÃO DA TERRA NA MICROBACIA DO RIACHO SERTÃOZINHO, PARAÍBA, BRASIL: SUBSÍDIOS PARA O PLANEJAMENTO AMBIENTAL
}

Victor Fellipe dos Santos GOMES ${ }^{\mathbf{1}}$; Niara Isis Pereira de OLIVEIRA ${ }^{\mathbf{1}}$; Nadjacleia Vilar ALMEIDA $^{2}$

\begin{abstract}
${ }^{1}$ Graduandos no Curso de Ecologia, Universidade Federal da Paraíba (UFPB), Campus IV, Litoral Norte, Centro de Ciências Aplicadas e Educação (CCAE), Rio Tinto, Paraíba, Brasil

${ }^{2}$ Doutora em Geografia. Universidade Federal da Paraíba (UFPB), Centro de Ciências Aplicadas e Educação (CCAE), Professora do Departamento de Engenharia e Meio Ambiente (DEMA), Laboratório de Cartografia e Geoprocessamento (LCG), Rio Tinto, Paraíba, Brasil
\end{abstract}

*Autor para correspondência. E-mail: souvictorgomes@hotmail.com

Resumo. Nas imediações da microbacia do Riacho Sertãozinho é notório a expansão de ocupações urbanas irregulares e ao longo da drenagem inúmeros usos da terra. A microbacia hidrográfica estudada é caracterizada por um rio intermitente e enquadra-se como Área de Preservação Permanente (APP). O objetivo do presente estudo é realizar um diagnóstico do uso e ocupação na Área de Preservação Permanente na microbacia do Riacho Sertãozinho, município de Mamanguape-PB. Foi realizada a delimitação da microbacia e foram utilizadas técnicas de fotointerpretação com imagens do Google Earth Pro para identificar a dinâmica espaço-temporal e o processo histórico do uso e ocupação da terra na APP. Com os levantamentos realizados foi possível constatar que ocorreu a ocupação irregular e consequente degradação nas APPs e no entorno do riacho. Contudo, nota-se que as principais problemáticas encontradas na microbacia do Riacho Sertãozinho são reflexo do uso e ocupação irregular da terra, sendo o PRAD importante para recuperação do equilíbrio ecológico local.

Palavras-chave: Análise espaço-temporal; Fotointerpretação; Google Earth Pro. 


\section{MULTI-TEMPORAL ANALYSIS OF LAND USE AND OCCUPATION IN THE RIACHO SERTÃoZINHO WATERSHED, PARAÍBA, BRAZIL: SUBSIDY FOR ENVIRONMENTAL PLANNING}

Abstract. In the vicinity of the Sertãozinho stream microbasin, the expansion of irregular urban occupations and numerous land uses along the drainage are notorious. The watershed studied is characterized by an intermittent river and fits as a Permanent Preservation Area (PPA). The objective of the present study is to carry out a diagnosis of the use and occupation in the Permanent Preservation Area in the Sertãozinho stream microbasin, municipality of Mamanguape-PB. The delimitation of the watershed was carried out and photointerpretation techniques were used with Google Earth Pro images to identify the space-time dynamics and the historical process of land use and occupation in the APP. With the surveys carried out, it was possible to verify that there was irregular occupation and consequent degradation in the APPs and around the creek. However, it is noted that the main problems found in the Sertãozinho stream microbasin are a reflection of the irregular use and occupation of the land, and the Plan for the Recovery of Degraded Areas-PRAD is important for the recovery of the local ecological balance.

Keywords: Spatio-temporal analysis; Photointerpretation; Google Earth Pro.

ANÁLISIS MULTITEMPORAL DEL USO Y OCUPACIÓN DEL SUELO EN LA CUENCA DEL ARROYO SERTÃOZINHO, PARAÍBA, BRASIL: SUBSIDIOS PARA LA PLANIFICACIÓN AMBIENTAL

Resumen. En las cercanías de la microcuenca del arroyo Sertãozinho, es notoria la expansión de ocupaciones urbanas irregulares y numerosos usos del suelo a lo largo del drenaje. La cuenca de estudio se caracteriza por un río intermitente y se encuadra como un Área de Preservación Permanente (APP). El presente estudio tiene como objetivo realizar un diagnóstico de uso y ocupación en el Área de Preservación Permanente en la microcuenca del arroyo Sertãozinho, municipio de MamanguapePB. Se realizó la delimitación de la cuenca y se utilizaron técnicas de fotointerpretación con imágenes de Google Earth Pro para identificar la dinámica espacio-temporal y el proceso histórico de uso y ocupación del suelo en la APP. Con los relevamientos realizados se pudo constatar que existía ocupación irregular y consecuente degradación en las APP y alrededores de la quebrada. Sin embargo, se observa que los principales problemas encontrados en la microcuenca del arroyo Sertãozinho son reflejo del uso y ocupación irregular del suelo, y el Plan de Recuperación de Áreas Degradadas-PRAD es importante para la recuperación del equilibrio ecológico local.

Palabras clave: Análisis espacio-temporal; Fotointerpretación; Google Earth Pro. 


\section{INTRODUÇÃO}

Conservação e planejamento ambiental no Brasil não é um tipo de discussão debatido recentemente. O processo histórico de conservação e planejamento ambiental no Brasil dá início no século XIX, quando naturalistas se preocupavam com questões ambientais locais, retratando tais modificações no ambiente através de pinturas a óleo visando à conservação dos ecossistemas naturais.

Para Santos (2004), o planejamento ambiental fundamenta-se na integração e interação dos sistemas que compõem o ambiente. Assim, é importante determinar o estado em que o meio está através do diagnóstico ambiental, definir o objetivo do planejamento e os indicadores e procedimentos metodológicos mais adequados. Somando-se com o pensamento de Conyers e Hills (1984), é um processo que envolve etapas, são elas: coleta, organização e análise sistemática dos dados, através de técnicas, para chegar à tomada de decisão ou trazer à tona, direções a respeito do melhor manejo dos recursos naturais. Para ambos os autores, o planejamento é um instrumento contínuo importante para a tomada de decisão, no qual, envolve estágios sequenciais e correlacionados dentro de etapas.

Simonds (1978) retrata que o planejamento ambiental é o direcionador da quantidade, da qualidade e da velocidade e natureza das trocas. Já Floriano (2004) compreende que é um processo de organização prévio de tarefas com base na ciência do passado como referência, para se atingir um objetivo vindouro. O planejamento para o referido autor, é porventura, a principal característica que diferencia o homem dos outros seres. $\mathrm{O}$ autor ainda retrata que o homem, por ser racional, tem a capacidade de analisar o que ocorreu em eventos anteriores e a partir disso, elaborar soluções para corrigir os atos feitos no passado.

Interpretar o planejamento ambiental como gestão ambiental é um erro bastante corriqueiro, destaca Santos (2004), visto que, gestão ambiental tem conexão com administração de empresas e instituições públicas ou privadas, a fim de inserir em seu escopo de gestão, práticas sustentáveis. O planejamento ambiental emaranha-se, muitas vezes, com o planejamento territorial; alguns autores declaram que não passa de uma extensão do planejamento setorial (urbano, institucional ou administrativo), e por fim acrescida da palavra ambiental (SLOCOMBE, 1993).

Para Santos (2004), o gerenciamento e o planejamento ambiental são fundamentais no processo de gestão dos recursos naturais, situa o planejamento como primeira etapa do processo e o gerenciamento nas etapas seguintes. No ponto de vista da autora, o diagnóstico e 
o prognóstico sobre a área de estudo sustentam o planejamento e o gerenciamento ambiental. A autora propõe que a gestão ambiental seja integrada ao planejamento, ao gerenciamento e a legislação ambiental.

O processo de organização do trabalho de uma equipe para alcance de objetivos comuns, de forma que, os impactos resultantes que afetam negativamente o ambiente em que vivemos sejam minimizados, foi chamado por Floriano (2004) de planejamento ambiental.

Dentre os conceitos supracitados, é notório que as definições de planejamento ambiental destacados, dentre os autores, se complementam. No que tange ao quesito temporal, o vínculo dos cenários: passado, presente e futuro; o objetivo comum do planejamento e, além disso, o mesmo deve fazer estimativas para eventos futuros.

De maneira geral, o planejamento ambiental ao passo que foi sendo destacado, é um processo que integra estágios, técnicas, informações e a tomada de decisão.

Assim, o objetivo geral é realizar um diagnóstico do uso e ocupação na Área de Preservação Permanente na microbacia do Riacho Sertãozinho, município de MamanguapePB. E os específicos são os seguintes: 1) Delimitar a microbacia e diagnosticar a situação da Área de Preservação Permanente; 2) Realizar análise espaço-temporal das alterações na cobertura do solo e sua relação com o estado atual da Área de Preservação Permanente (APP) na microbacia; e, 3) Averiguar o histórico do processo de ocupação urbana na área de APP da microbacia do Rio Sertãozinho.

\section{MATERIAL E MÉTODOS}

\section{Área de estudo}

A área de pesquisa (Fig. 1) corresponde a microbacia do Riacho Sertãozinho que está localizada no município de Mamanguape-PB, depressão sub-litorânea do Estado da Paraíba, está situada na microrregião do Litoral Norte, distante 50km da Capital João Pessoa-PB. A cidade de Mamanguape, sede do município tem atualmente uma área de $480 \mathrm{Km}^{2}$, com as seguintes coordenadas geográficas: 6050'30' de latitude sul e 35'7' 30 ' de longitude oeste. Mamanguape está dentro de regiões de zona de mata (COSTA, 1992). De acordo com o último censo demográfico realizado pelo IBGE (Instituto Brasileiro de Geografia e Estatística) de 2010, o município de Mamanguape tem aproximadamente 42.303 habitantes (IBGE, 2010). No entanto, desde 2003, faz parte da Região Metropolitana de João Pessoa-PB. 


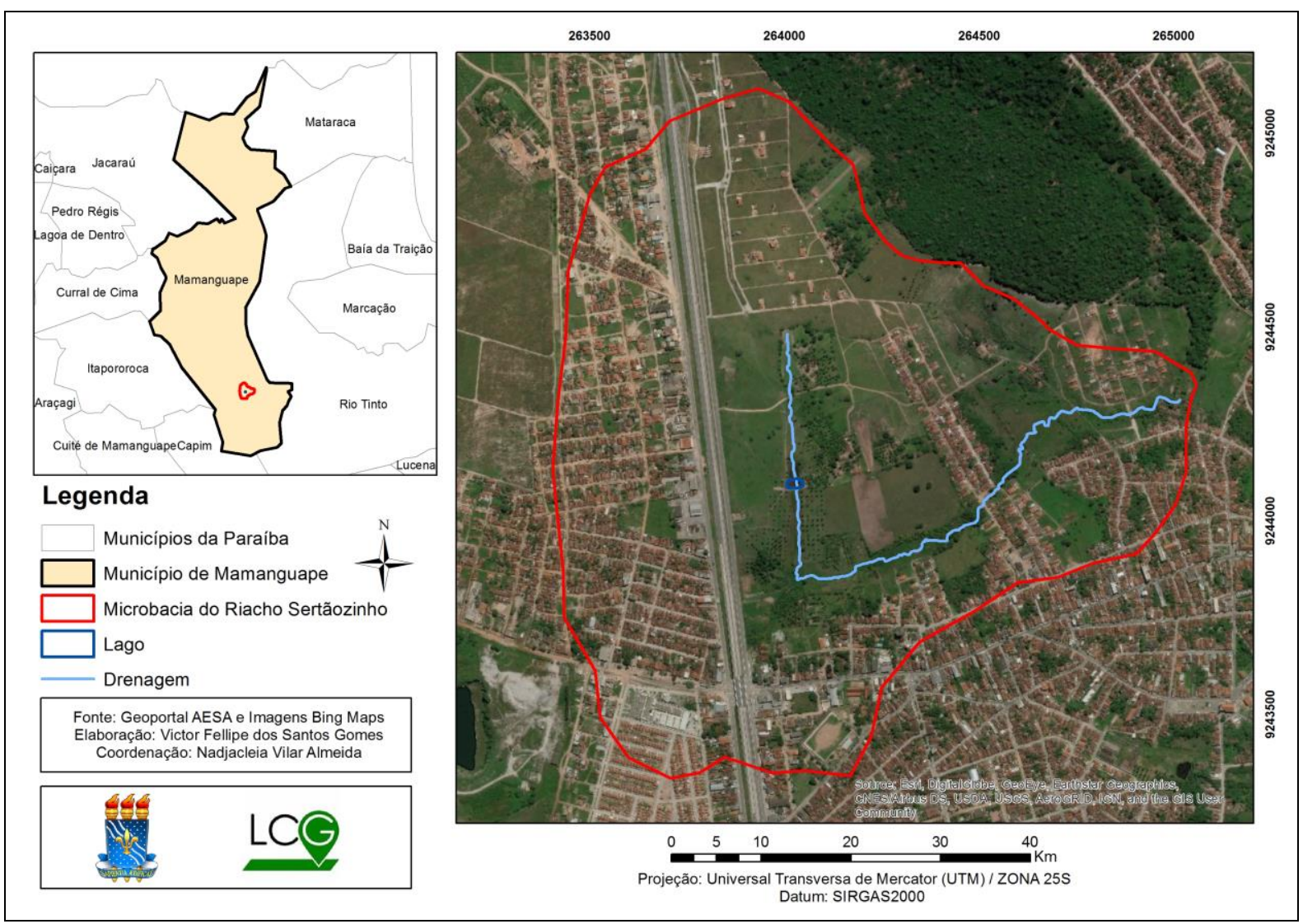

Figura 1. Localização da microbacia do Riacho Sertãozinho, cidade de Mamanguape, estado da Paraíba, Nordeste do Brasil. Fonte: Geoportal AESA, Imagens Google Earth, Digital Globe.

Na área de estudo de acordo com Lima (2013), no que tange, a caracterização vegetativa, são encontrados dois tipos: a Mata Latifoliada Perenifólia Costeira (Mata Atlântica), fragmentadas com Mata de tabuleiro (Hiléia Baiana).

\section{Abordagem para Georreferenciamento}

No desenvolvimento da presente pesquisa foram utilizados os seguintes materiais: a carta topográfica do município de Itapororoca-PB (Folha SB.25-Y-A-V-4-NO) elaborada pela SUDENE (Superintendência de Desenvolvimento do Nordeste) na escala de 1:25.000 e publicada no ano de 1974. Arquivos shapefile referentes aos limites municipais do Estado da Paraíba, adquirido no GeoPortal AESA (Agência Executiva de Gestão de Águas do Estado da Paraíba). Quanto aos materiais necessários para a aplicação dos procedimentos metodológicos, fez-se necessário a utilização de software ArcGIS, versão 10.6.

Para o trabalho de fotointerpretação seguiu-se sob análise observacional realizada, in loco, de pesquisas no software Google Earth Pro em conjunto com o software ArcGIS. O 
software Google Earth Pro é livre e gratuito, no qual foram capturadas imagens aéreas coloridas da localidade para interpretar e comparar as mudanças na área de estudo.

Para a etapa de campo, utilizou-se: um aparelho GPS (Global System Position) de navegação e fichas de campo para descrição da área quanto ao uso e ocupação.

\section{Procedimentos metodológicos}

\section{DELIMITAÇÃO DA MICROBACIA, IDENTIFICAÇÃO DE DRENAGEM, NASCENTE E} APP

Para visualizar e interpretar as alterações encontradas na área de estudo e relacioná-las à ocupação urbana e aos eventuais impactos ambientais emergentes na APP, utilizou-se como procedimento os princípios de fotointerpretação no ambiente SIG (Sistema de Informação Geográficas). A princípio, foi-se georreferenciado a carta topográfica do município de Itapororoca-PB com o auxílio do ArcMAP, que vem no pacote do ArcGIS 10.6. Seguiu-se a inserção de pontos de controle em vários pontos da carta, utilizando as coordenadas geográficas destes pontos. Para o georreferenciamento das imagens do Google Earth Pro seguiu-se o mesmo plano, foi coletado as coordenadas geográficas do próprio programa em projeção Universal Transversa de Mercator (UTM) e plotados no ArcMAP, nas mesmas localizações. Com a usabilidade da ferramenta Georreferecing e Rectify para salvar os pontos.

Através da carta topográfica delimitou-se a microbacia do Riacho Sertãozinho conectando os pontos cotados, tendo como referência o compartamento das curvas de nível. Em ato contínuo, realizou-se a identificação da rede de drenagem e da nascente, foi delimitada através das ferramentas de vetorização do ArcMAP.

Para delimitação da Área de Preservação Permanente dentro da microbacia hidrográfica em estudo, a priori foram adquiridas informações a respeito da Lei Federal Brasileira $n^{\circ} 12.651$, de 25 de maio de 2012 para APP, das técnicas em geoprocessamento e das políticas públicas voltadas para a gestão de APP, conforme o Novo Código Florestal Brasileiro (BRASIL, 2012). Em seguida foram utilizados arquivos georreferenciados, assim como imagens do Google Earth Pro e outros materiais que contribuíssem no processo de identificação e delimitação da APP, como artigos científicos.

Para execução da delimitação da Área de Preservação Permanente foi utilizado o software ArcGIS 10.6. 


\section{ESPACIALIZAÇÃO DO USO E COBERTURA DA TERRA}

Com o propósito de interpretar a evolução da interação socioambiental na microbacia do Riacho Sertãozinho ao longo dos anos, realizou-se a espacialização do uso e cobertura da terra com base na digitalização do documento cartográfico mais antigo disponível: a carta topográfica de Itapororoca-PB. Com esta finalidade, foram utilizadas as ferramentas de vetorização do ArcMAP que nos possibilita a criação e edição de camadas vetoriais.

Dessa forma, gerou-se o mapa do uso e cobertura da terra da microbacia do Riacho Sertãozinho no ano de 1974. As classes identificadas a partir da carta topográfica auxiliaram a fotointerpretação das imagens do Google Earth Pro, no que se refere a localização das áreas ocupadas na microbacia.

Para a análise e interpretação das imagens, empregou-se a utilização das imagens do Google Earth Pro e carta topográfica georreferenciada. Com base nisso, foram mapeados o uso e a cobertura da terra dos cenários de 1974, 2015 e 2019. Este procedimento está subdividido em duas etapas, sendo estas: Por meio de um software SIG, as imagens de satélite foram digitalizadas e georreferenciadas; realizou-se o mapeamento temático das classes de uso e cobertura da terra e dos impactos ambientais definidas na etapa anterior. Após a criação do mapeamento temático para cada ano, por meio da etapa de intersecção, foram calculadas as áreas de cada classe integrada a microbacia hidrográfica para cada ano e dentro da APP no ano vigente.

\section{Análise histórica do processo de ocupação urbana na microbacia}

Operações de coleta de dados disponíveis, através de análise documental na Biblioteca Municipal de Mamanguape à procura de bibliografias, documentos municipais, mapas cartográficos do município, artigos científicos, sites confiáveis, dentre outros.

\section{RESULTADOS E DISCUSSÃO}

A microbacia do Riacho Sertãozinho possui uma área total de $1,85 \mathrm{~km}^{2}$. A espacialização do uso e cobertura da terra na microbacia do Riacho Sertãozinho no ano de 1974 é apresentada pela Figura 2. 


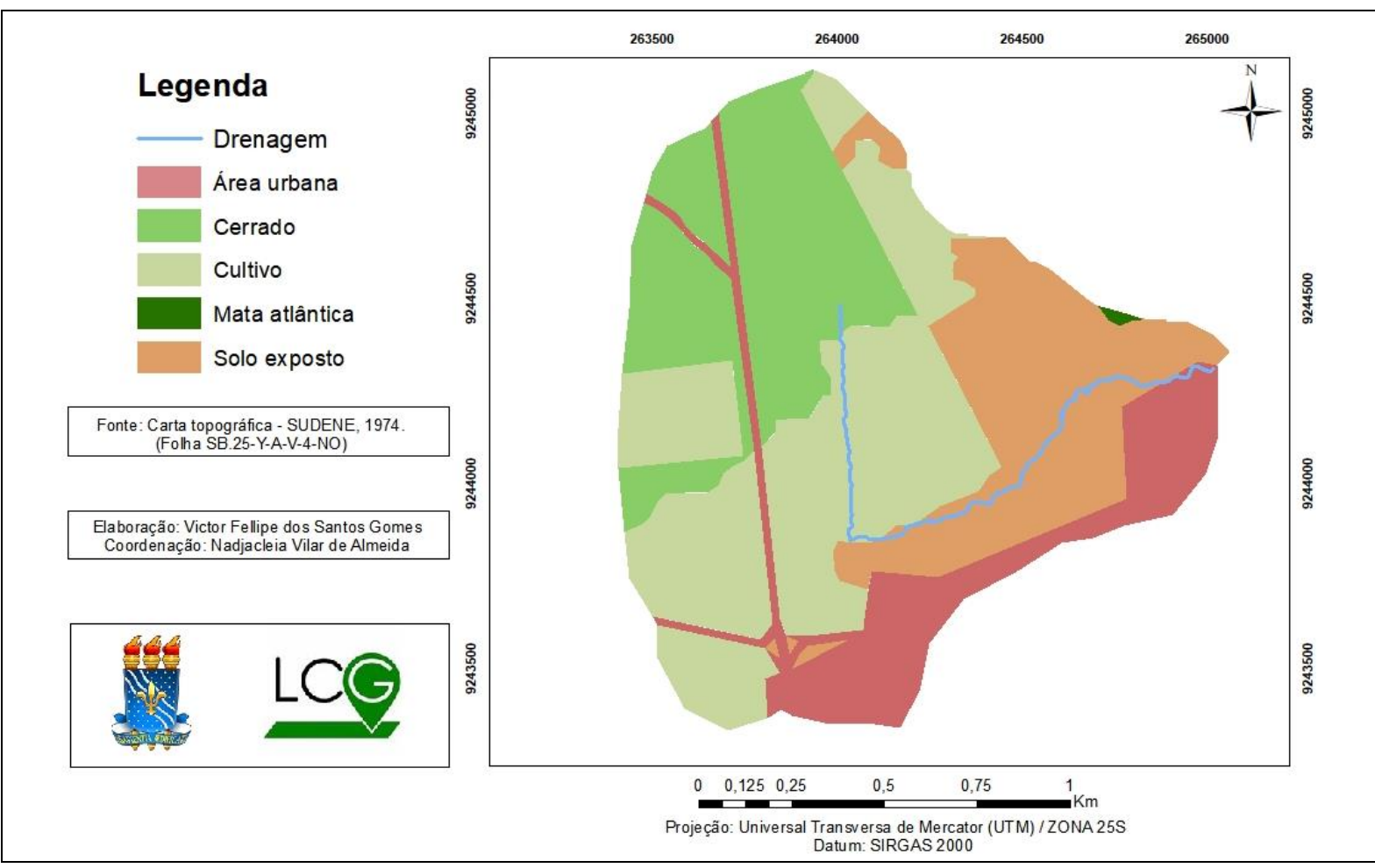

Figura 2. Uso e cobertura da terra da microbacia do Riacho Sertãozinho em 1974. Fonte: Carta topográfica, folha de Itapororoca, estado da Paraíba, Nordeste do Brasil.

No que diz respeito à cobertura vegetal, constata-se que as classes com maior expressão foram: Tabuleiro, na carta está representado por Cerrado, ocupando 24,91\% da área da microbacia e a Mata Atlântica apenas $0,11 \%$. No que tange ao uso, o Cultivo, principalmente por plantio de canaviais, ocupava 36,99\% da área da Microbacia em 1974, enquanto o Solo Exposto ocupava 22,25\%. Averiguou-se também a presença de Área Urbana na carta, apresentada com $15,74 \%$ da área da microbacia, que abrange o início da comunidade Terra Nova e Centro. Os valores de área para cada classe estão expostos na Tabela 1, a seguir.

Tabela 1: Quantificação do uso e cobertura da terra da microbacia do Riacho Sertãozinho em 1974. Fonte: Carta topográfica, folha de Itapororoca, estado da Paraíba, Nordeste do Brasil.

\begin{tabular}{ccc}
\hline \multirow{2}{*}{ CLASSES } & \multicolumn{2}{c}{ CARTA (1974) } \\
\cline { 2 - 3 } & Área $\left(\mathbf{k m}^{\mathbf{2}}\right)$ & $\%$ \\
ÁREA URBANA & 0,29 & 15,74 \\
CERRADO & 0,46 & 24,91 \\
CULTIVO & 0,66 & 36,99 \\
MATA ATLÂNTICA & 0,03 & 0,11 \\
SOLO EXPOSTO & 0,41 & 22,25 \\
\hline TOTAL & $\mathbf{1 , 8 5}$ & $\mathbf{1 0 0}$ \\
\hline
\end{tabular}


A espacialização do uso e cobertura da terra em 1974 retrata o cenário da microbacia do Riacho Sertãozinho. Esse mapeamento foi crucial para corroborar com a classificação supervisionada dos anos seguintes, do mesmo modo que, também, permita esclarecer a dinâmica do uso e ocupação da terra. Por conseguinte, realizou-se a classificação supervisionada para os anos de 2015 e 2019 (Fig. 3). Com a finalidade de explicitar as transformações ocorridas na microbacia do Riacho Sertãozinho no decorrer de quarenta e cinco anos, especificamente, quatro décadas.

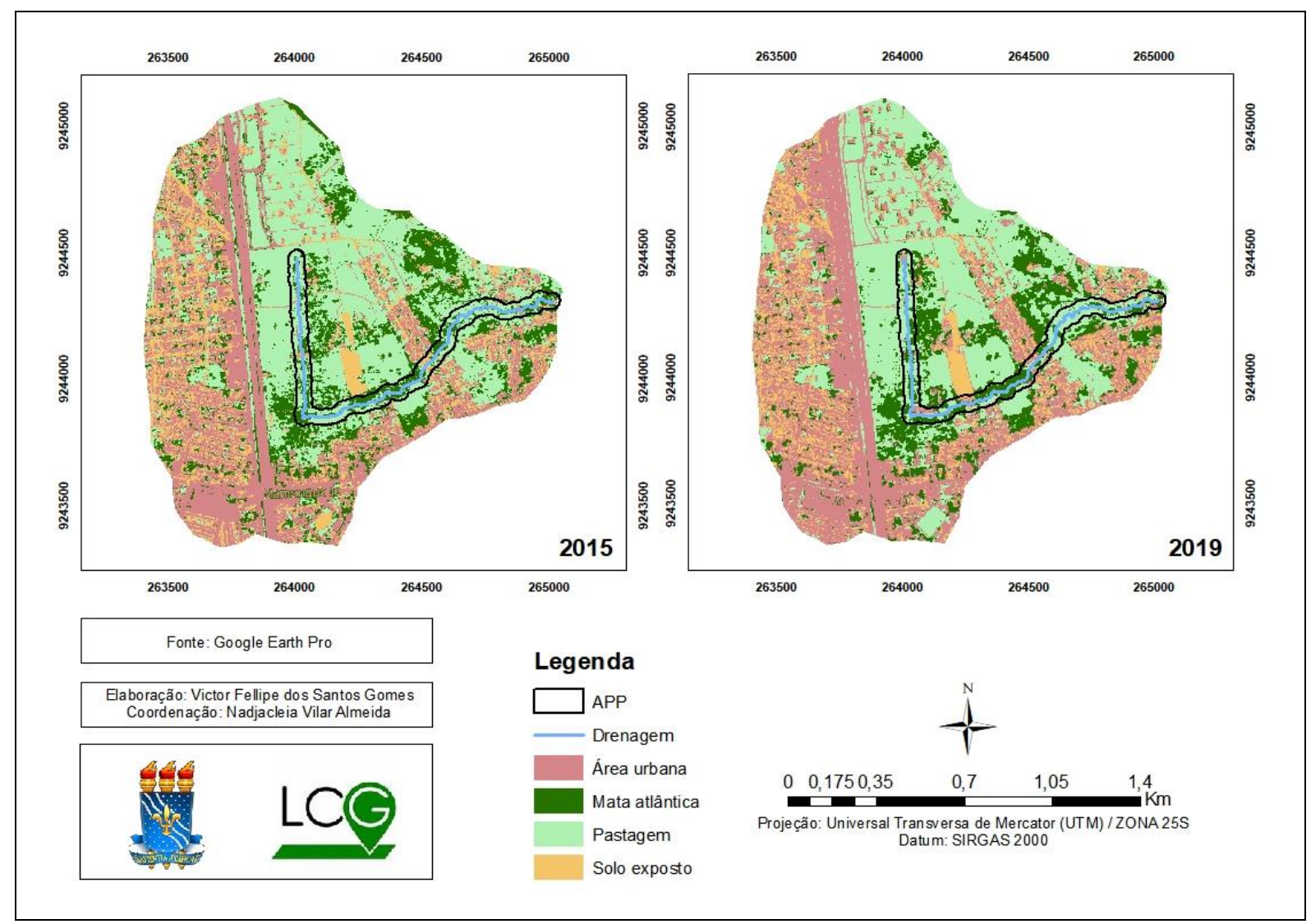

Figura 3. Uso e ocupação da terra da microbacia do Riacho Sertãozinho (2015 a 2019), Nordeste do Brasil. Fonte: Dados da pesquisa.

Ao comparar a classificação supervisionada do ano de 2015 com o mapeamento de 1974, percebe-se de imediato que em quarenta e um anos a classe Cerrado foi totalmente substituída por Pastagem, Área Urbana e Solo Exposto. Farias (2013) afirma que: "a cidade de Mamanguape tem provocado modificações em sua dinâmica espacial, com o surgimento de loteamentos e valorização imobiliária". Diante do cenário exposto, é pertinente fazer a associação da fala de Farias (2013) com o respectivo resultado, visto que, ao longo do processo histórico de formação da malha urbana da cidade de Mamanguape houve instalações 
de empreendimentos próximos a microbacia, como a Escola Cidadã Integral Técnica - João da Matta Cavalcanti de Albuquerque (ECIT-MME) no ano de 2015, e dentro da microbacia o Hospital Geral de Mamanguape (HGM) no ano de 2014 e o Loteamento Vista Bela. Fato que faz referência ao aumento de empregabilidade e a demanda de novas moradias próxima a essas instalações, simultaneamente, a área torna-se sujeita ao avanço da ocupação urbana dentro da microbacia hidrográfica e no entorno da APP.

Com base na quantificação das áreas ocupadas por cada classe, constata-se também uma progressiva redução de Solo Exposto de 1974 a 2019. No ano de 1974, o Solo Exposto ocupava 22,25\%, em 2015 caiu para $13,17 \%$ e no ano seguinte decaiu 1,21\% da área de abrangência totalizando em 2019, 11,96\%. O decréscimo dessa classe ocorreu pelo avanço da ocupação urbana. Isso se dá também para a classe Pastagem, no ano de 2015 apresentava ocupação de 38,49\% da área, sendo representada em 2019 com 36,04\%, tais reduções claramente foram substituídas por Área Urbana. Dentre os anos de 1974 a 2019, a classe Área Urbana foi a mais expressiva, como é possível observar na Tabela 2.

Tabela 2. Quantificação do uso e cobertura da terra na microbacia do Riacho Sertãozinho (1974 a 2019), Nordeste do Brasil. Fonte: Dados da pesquisa.

\begin{tabular}{ccc|cccc}
\hline CLASSES & CARTA (1974) & $\begin{array}{c}\text { GOOGLE } \\
\text { EARTH } \\
(\mathbf{2 0 1 5})\end{array}$ & \multicolumn{2}{c}{$\begin{array}{c}\text { GOOGLE } \\
\text { EARTH (2019) }\end{array}$} \\
\hline & & \multicolumn{7}{c|}{ ÁREA } \\
\hline ÁREA URBANA & 0,29 & 15,74 & 0,56 & 30,44 & 0,68 & 36,77 \\
PASTAGEM & - & - & 0,71 & 38,49 & 0,67 & 36,04 \\
CERRADO & 0,46 & 24,91 & - & - & - & - \\
CULTIVO & 0,66 & 36,99 & - & - & - & - \\
MATA ATLÂNTICA & 0,66 & 36,99 & 0,34 & 17,90 & 0,28 & 15,23 \\
SOLO EXPOSTO & 0,03 & 0,11 & 0,24 & 13,17 & 0,22 & 11,96 \\
\hline TOTAL & $\mathbf{0 , 4 1}$ & $\mathbf{2 2 , 2 5}$ & $\mathbf{1 , 8 5}$ & $\mathbf{1 0 0}$ & $\mathbf{1 , 8 5}$ & $\mathbf{1 0 0}$ \\
\hline
\end{tabular}


Quanto à Mata Atlântica, em 1974 ocupava apenas 0,11\% da bacia, obteve um acréscimo de 17,90\% em 2015 e no ano seguinte decaiu cerca de 3\%, em relação a 2015. Vale ressaltar que o software confundiu algumas assinaturas espectrais na classificação supervisionada, principalmente regiões de Mata Atlântica ocasionando uma confusão espectral entre as áreas de Mata Atlântica com áreas de bosque e plantações de coqueiro.

No mapeamento das classes no ano de 1974, a microbacia do Riacho Sertãozinho apresentava três classes: Cerrado, Cultivo e Solo Exposto, mas nenhuma ocorrência de Mata Ciliar no entorno da microbacia. Para os anos de 2015 e 2019, é notório que a classe Mata Atlântica teve grande conquista no espaço, uma suposição poderá ser levantada na seguinte inquisição: que animais dispersores de sementes, de galhos, e plântulas de espécies nativas de Mata Atlântica podem ter passado pelo local e deixado tais elementos tombar no solo ou a população na qual foi se instalando ao longo dos anos, conseguiu plantar espécie nativa de Mata Atlântica, visto que, outrora, a população mamanguapense tinha livre acesso a Mata do Sertãozinho (próximo à região de estudo), onde também se encontra a nascente do Riacho Sertãozinho, que dá o nome ao mesmo.

Já na classe Cultivo, segundo Costa (1992), Mamanguape passou por três ciclos econômicos predominantes na Paraíba, como o do algodão, do couro, do fumo e principalmente da cana-de-açúcar, tornando-a, a mesma responsável pelo enorme agente de desenvolvimento econômico da cidade.

À vista disso, conservando a tradição do cultivo de cana-de-açúcar, Mamanguape continuou a produzir rapadura e fabricar aguardentes. No entanto, para manutenção dessa monocultura era necessário um espaço geográfico para a implantação canavieira, mesmo em pequena escala. Em 1974, a classe Cultivo está representada com 36,99\% de toda a área da microbacia, condição que faz jus à menção de Costa (1992). Silva (2011) menciona que o auge econômico e urbano de Mamanguape se caracterizava, principalmente, pelo êxito dos cultivos de cana, em outras palavras, retratando adequadamente sobre o cenário do plantio canavieiro em Mamanguape naquela época.

Não demorou muito para que grandes investidores visassem as terras e a cidade de Mamanguape como uma grande fonte promissora na indústria canavieira. Trazendo consigo grandes famílias de várias regiões do Brasil, que investiram na construção de engenhos açucareiros, usinas e destilarias (COSTA, 1992; SILVA, 2011). Oportunizando a tais indústrias, a exemplo da Açúcar Alegre, a aquisição de novos hectares de terra para o plantio e inviabilizando os pequenos produtores dessa monocultura, que não havia capital disponível para investimentos. Apesar disso, uma nova atividade foi conquistando os espaços 
mamanguapenses - a pecuária. A cria e venda de gado, segundo Silva (2011), foi um dos caminhos de interesse para a população citadina, isto, para aqueles que não tinham condições econômicas. Desta maneira, a pecuária em Mamanguape só foi praticável em virtude as crescentes áreas de pastagens desocupadas e improdutivas que passaram a ser úteis nesta produção econômica, até então não praticada.

Ao comparar os mapeamentos de 1974 a 2019, é possível constatar mudanças drásticas no uso e cobertura da terra, perda de Cerrado e Cultivo oportunizando espaços para Pastagem onde observamos algumas áreas planas reservadas exclusivamente a pecuária (principalmente bovinos, caprinos e equinos) e grande parte da área ocupada por Área Urbana.

\section{CONSIDERAÇÕES FINAIS}

Os resultados alcançados mostraram, que a microbacia do Riacho Sertãozinho se encontra em um estado de degradação progressiva decorrente das pressões urbanas no entorno da APP.

A utilização de técnicas de fotointerpretação mostrou ser viável no estudo proposto como a identificação da rede de drenagem, o uso/ocupação do solo, estado de erosão, degradação nas vegetações nativas e matas ciliares, contribuiu para caracterizar o estado da APP de uma área urbana, que quando relacionado à mensuração das áreas de uso e cobertura da terra, serve de subsídio para um planejamento ambiental na APP.

Com o auxílio do programa Google Earth Pro, foi possível realizar a classificação supervisionada. A partir da análise da distribuição das classes de uso e cobertura da terra, ao longo de um período de quarenta e cinco anos, conclui-se que as interferências antrópicas na microbacia do Riacho Sertãozinho, possui estreita relação com o estado da APP desta microbacia, responsáveis por violações que geram a degradação ambiental. As modificações no uso e cobertura da terra causam impactos na microbacia, principalmente quando as APPs são tomadas por residências irregulares durante o processo de urbanização, ampliando as áreas com o solo exposto.

Contudo, é necessário que seja realizado um trabalho de educação ambiental que permita a população local conhecer a importância da preservação da APP e juntamente com os governos municipal e estadual garantir a conservação das áreas naturais na microbacia. 


\section{DECLARAÇÃO DE CONTRIBUIÇÃO DE CRÉDITO DE AUTORIA}

Conceptualização: VFSG, NIPO, NVA, Curadoria de dados: VFSG, NIPO, NVA, Análise formal: $N V A$, Metodologia: VFSG, NIPO, NVA, Administração de projetos: NVA, Escrita: VFSG, NIPO, NVA, Análise formal: NVA, Validação: NVA.

\section{DECLARAÇÃO DE INTERESSE}

Os autores revelam que não possuem interesses financeiros concorrentes conhecidos ou relações pessoais que possam parecer ter influenciado o estudo relatado neste manuscrito.

\section{FONTE DE FINANCIAMENTO}

Os autores declaram que nenhum financiamento é aplicável a esta pesquisa.

\section{REFERÊNCIAS}

BRASIL. Lei no 12.651 , de 25 de maio de 2012. Dispõe sobre a proteção da vegetação nativa; altera as Leis $\mathrm{n}^{\mathrm{o}} \mathrm{s}$ 6.938, de 31 de agosto de 1981, 9.393, de 19 de dezembro de 1996, e 11.428, de 22 de dezembro de 2006; revoga as Leis $\mathrm{n}^{\circ} \mathrm{s} 4.771$, de 15 de setembro de 1965, e 7.754, de 14 de abril de 1989, e a Medida Provisória n².166-67, de 24 de agosto de 2001; e dá outras providências. Presidência da República Federativa do Brasil: Brasília, 15 mai. 2012. Disponível em: http://www.planalto.gov.br/ccivil_03/_ato20112014/2012/lei/112651.htm. Acesso em: 22 jun. 2022.

CONYERS, D.; HILLS, P. An introduction to development planning in the third world. New York: John Wiley \& Sons, v. 4, n. 2. 1984.

COSTA, A.C. Mamanguape minha terra. Estudos sociais. 1. ed. Edição ilustrada. Paraíba: Gráfica JB, 1992.

FARIAS, R.S.D. A centralidade de Mamanguape (PB) e sua relação com as cidades pequenas do litoral norte paraibano. (Dissertação de mestrado em geografia) Universidade Federal da Paraíba, 2013. 
FLORIANO, E.P. Planejamento ambiental. Caderno Didático, n. 6, p. 1, 2004.

IBGE. Censo demográfico 2010. Instituto Brasileiro de geografia e Estatística. 2010. Disponível em: https://cidades.ibge.gov.br/brasil/pb/mamanguape/panorama. Acesso em: 24 set. 2020 .

LIMA, E.J. Levantamento do quadro natural do Município de Mamanguape-PB. Monografia (Trabalho de Conclusão do Curso de Geografia) - Universidade Federal da Paraíba, 2013.

SANTOS, R.F. Planejamento Ambiental: teoria e prática. 1. ed. São Paulo: Oficina de Textos, 184p., 2004.

SILVA, A.C.S. As mudanças sociais derivadas da duplicação da BR 101 na área urbana do município de Mamanguape-PB. Monografia (Trabalho de Conclusão de Curso) Universidade Estadual da Paraíba, 2011.

SIMONDS, J.O. Earthscape: a manual of environmental planning. 1. ed. McGraw-Hill Companies, 340p. 1978.

SLOCOMBE, D.S. Environmental planning, ecosystem science and ecosystem approaches for integrating environment and development. Environmental Management, v. 17, n. 3, p. 289-303, 1993. 